\title{
Patient handover in a European border region: Cross- sectional survey study among healthcare workers to explore the status quo, potential risks, and solutions
}

Citation for published version (APA):

Bouwmans, M. E. J., Beuken, J. A., Verstegen, D. M. L., van Kersbergen, L., Dolmans, D. H. J. M., Vogt, L., \& Sopka, S. (2021). Patient handover in a European border region: Cross-sectional survey study among healthcare workers to explore the status quo, potential risks, and solutions. International Journal of Care Coordination, 24(2), 72-81. [20534345211009434]. https://doi.org/10.1177/20534345211009434

Document status and date:

Published: 01/06/2021

DOI:

10.1177/20534345211009434

Document Version:

Publisher's PDF, also known as Version of record

Document license:

Taverne

Please check the document version of this publication:

- A submitted manuscript is the version of the article upon submission and before peer-review. There can be important differences between the submitted version and the official published version of record.

People interested in the research are advised to contact the author for the final version of the publication, or visit the DOI to the publisher's website.

- The final author version and the galley proof are versions of the publication after peer review.

- The final published version features the final layout of the paper including the volume, issue and page numbers.

Link to publication

\footnotetext{
General rights rights.

- You may freely distribute the URL identifying the publication in the public portal. please follow below link for the End User Agreement:

www.umlib.nl/taverne-license

Take down policy

If you believe that this document breaches copyright please contact us at:

repository@maastrichtuniversity.nl

providing details and we will investigate your claim.
}

Copyright and moral rights for the publications made accessible in the public portal are retained by the authors and/or other copyright owners and it is a condition of accessing publications that users recognise and abide by the legal requirements associated with these

- Users may download and print one copy of any publication from the public portal for the purpose of private study or research.

- You may not further distribute the material or use it for any profit-making activity or commercial gain

If the publication is distributed under the terms of Article 25fa of the Dutch Copyright Act, indicated by the "Taverne" license above, 


\title{
Patient handover in a European border region: Cross-sectional survey study among healthcare workers to explore the status quo, potential risks, and solutions
}

International Journal of Care Coordination 2021, Vol. 24(2) 72-8I (C) The Author(s) 2021 Article reuse guidelines: sagepub.com/journals-permissions DOI: I0.1 I77/205343452II009434 journals.sagepub.com/home/icp @AGE

\author{
Mara EJ Bouwmans' (D, Juliëtte A Beuken', \\ Daniëlle ML Verstegen', Laura van Kersbergen², \\ Diana HJM Dolmans', Lina Vogt ${ }^{2}$ and Saša Sopka ${ }^{2}$
}

\begin{abstract}
Introduction: While the popularity of international care is rising, the complexity of international care compromises patient safety. To identify risks and propose solutions to improve international care, this study explores experiences of healthcare workers with international handovers in a European border region.

Methods: A cross-sectional survey design was used to reach out to 3000 healthcare workers, working for hospitals or emergency services in three neighboring countries in the Meuse-Rhine Euregion. In total, 846 healthcare workers completed the survey with 35 closed- and open-ended questions about experiences with international patient handover. Results: One-third of respondents had been involved in international handover in the previous month. The handovers occurred in planned and acute care settings and were supported by numerous, yet varying standardized procedures. Healthcare workers were trained for this in some, but not all settings. Respondents mentioned 408 risks and proposed 373 solutions, which were inductively analyzed. Six identified themes classify the level on which risks and accompanying solutions can be found: awareness, professional competencies, communication between professionals, loss of information, facilities and support, and organizational structure.

Discussion: This study gives insight in international patient handovers in a European border region. Among the biggest risks experienced are procedural differences, sharing patient information, unfamiliarity with foreign healthcare systems, and not knowing roles and responsibilities of peers working across the border. Standardization of procedures, harmonization of systems, and the possibility for healthcare workers to get to know each other will contribute to reach common ground and move towards optimized and patient-safer cross-border care.
\end{abstract}

\section{Keywords}

Cross-border care, cross-sectional survey, needs assessment, patient handoff, patient safety

\section{Introduction}

The number of patients crossing the border for healthcare is expected to increase in the coming decade, which hypothetically benefits healthcare. ${ }^{1,2}$ Cross-border mobility is becoming more and more popular in the European Union, where free movement of people and services across borders is one of the fundamental features of society. Residents can travel between countries quite easily, which facilitates the option to work in one country and live in another one, or to go across the border for recreative purposes. This also holds for healthcare, where patients more easily decide for themselves to seek healthcare across the border. In 2016 it was reported that on average $33 \%$ of European citizens was willing to cross a border to

\footnotetext{
'Maastricht University, the Netherlands

${ }^{2}$ RWTH Aachen University, Germany

Corresponding author:

Mara EJ Bouwmans, Dept. of Educational Development and Research, Faculty of Health, Medicine and Life Sciences, Maastricht University, P.O. Box 616, 6200 MD Maastricht, the Netherlands.

Email: marabouwmans@gmail.com
} 
receive healthcare, ${ }^{2}$ and only in the region the Benelux almost 170,000 patients cross the border for healthcare reasons every year.

Patients may receive treatment across the border for two types of care: elective (planned) and acute (unplanned). ${ }^{3}$ In the case of elective care, arguments to cross the border include bypassing waiting lists, accessing procedures not performed in the country of residence, or seeking a specialized physician. ${ }^{4}$ Volume requirements are leading to more centralized professional expertise, but less availability of certain specialties close to home. In the case of rare diseases or the need for specialist surgery, patients could cross the border for treatment in the nearest, specialized care facility. ${ }^{5}$ Similarly, in the case of acute care, a hospital outside the country of residence is sometimes preferred because it is closer or provides a more advanced level of care. For example, a person suffering from severe trauma caused by an accident near the border may be admitted to the closest level-one trauma center right across the border. These benefits are especially relevant in border-regions, where healthcare providers from different countries are relatively close together.

Although international healthcare is often beneficial, the complexity of patient handovers in an international context ${ }^{6}$ may negatively influence patient safety in these situations. ${ }^{7}$ Patient handover, also known as clinical handover or handoff, refers to the shift of professional responsibility and accountability for (some or all aspects of) care for a patient/group of patients to another person or professional group on a temporary or permanent basis. ${ }^{8,9}$ It is commonly acknowledged that patient handover in itself forms one of the largest patient safety risks if it is not performed adequately. ${ }^{10}$ Inadequate handover is associated with $25-40 \%$ of adverse events in hospitals, and theories addressing patient safety risks mention several handover-related factors. ${ }^{11}$ Unreliable inter-professional communication has recently been shown to be one of the major factors influencing a patient-safe clinical handover. ${ }^{12,13}$ To reduce patient safety issues, the WHO Collaborating Centre for Patient Safety Solutions mentioned improved communication as one of the top priorities in handovers. ${ }^{14}$ Although a lot is known about handover in general, and risks associated with them, it is unclear how this translates to international patient handovers.

Earlier studies focused on international healthcare throughout Europe, while benefits and risks are especially relevant in border-regions. Cross-border collaboration is highly context-dependent and driven by local needs. ${ }^{15}$ In border-regions, healthcare providers are situated relatively close together and healthcare workers might be more acquainted with international healthcare and handover. One study investigated the experiences of healthcare workers specifically in European border regions. ${ }^{1}$ Here, medical specialists explicitly voiced the need for standardized discharge reports, harmonized IT systems, and more support from the overarching systems to improve international healthcare. Although these studies gave insights into factors that might enhance international healthcare in border-regions, it lacked specific focus on handover. A recent study, in settings where collaboration across borders is already the order of the day, showed that healthcare workers also struggle with these topics during patient handover. ${ }^{16}$ Since this is a crucial and hazardous moment in the transfer of patients in the international setting, it is vital to find out which additional factors might enhance or hinder international patient handovers, and how to resolve patient safety risks. The aim of this study is to (1) investigate the current situation regarding international patient handovers in a European border region, asking healthcare workers about experiences with local handover, international handover, procedures and checklists used, safety culture, and training, and to (2) explore the perceptions of healthcare workers about the risks and possible solutions regarding international patient handovers in their region.

\section{Methods}

This cross-sectional survey study was performed in the European border-region Meuse-Rhine, where Belgium, Germany and the Netherlands meet. This region has been a pioneer in cross-border collaboration since it was established in the 1970 s. ${ }^{4}$ The region has a leading role in international healthcare collaboration, ${ }^{17,18}$ where international healthcare is well-developed. The region is therefore interesting to study the phenomenon of international patient handovers and the associated safety risks and solutions.

\section{Setting}

The current study ran from September 2017 until the end of January 2018. Four large hospitals were involved: CHR de la Citadelle (CHR) Liège in Belgium, Maastricht University Medical Center (MUMC+) in the Netherlands, the Uniklinik RWTH Aachen (RWTH) in Germany, and Ziekenhuis OostLimburg (ZOL) in Genk, Belgium. Emergency services in the Aachen region of Germany, the provinces of Limburg and Liège in Belgium, and the Dutch province of Zuid-Limburg also participated (See Figure 1). 


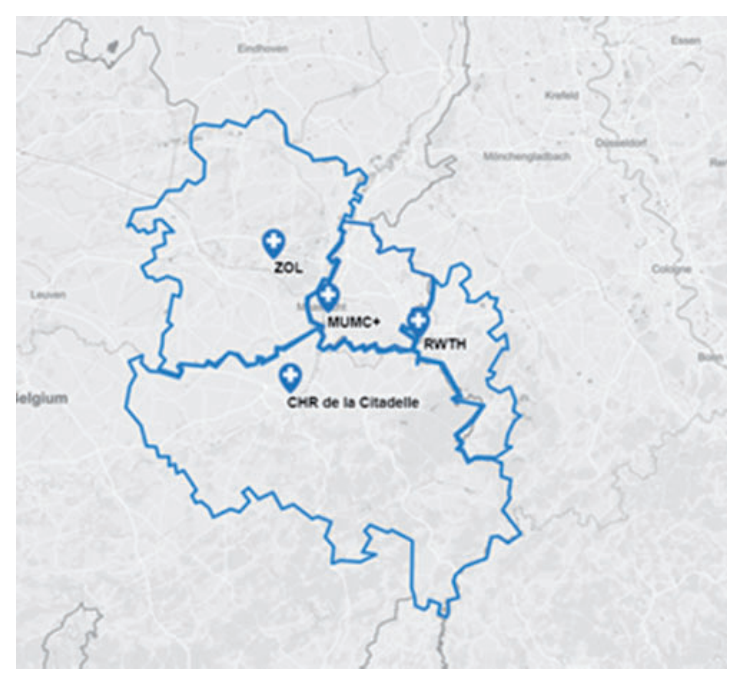

Figure I. Hospitals and regions involved in the general handover survey.

CHR de la Citadelle: le Centre Hospitalier Régional de la Citadelle, Belgium; MUMC+: Maastricht University Medical Center, Netherlands; RWTH: University Hospital RWTH Aachen, Germany; ZOL: Ziekenhuis Oost-Limburg Genk, Belgium.

\section{Respondents}

The researchers reached out to administrative staff, managers, medical doctors, nurses, and paramedics working in a hospital or for an emergency service in the Euregion Meuse-Rhine at the time of participation. All respondents are referred to as 'healthcare workers' in this study.

\section{Instruments}

A questionnaire named the General Handover Survey (GHS) was developed, deriving some items from an existing questionnaire. ${ }^{19}$ The GHS was piloted by healthcare workers working on the SafePAT project, and translated from English into Dutch, French, and German. Two versions of the Dutch translation were developed: one adapted to terminology used in the Dutch healthcare system, the other to the Flemish healthcare system. An online survey system (Qualtrics, Provo, UT) was used to collect data.

The GHS took approximately ten minutes to complete. It contains 35 items, both closed- and openended questions, divided over seven categories: (1) demographics, (2) local handover, (3) international handover, (4) procedures/checklists, (5) safety culture, (6) training, (7) risks and solutions. The closed questions address the status quo of international patient handovers and the way it relates to general handover. The open questions address the potential risks and solutions.
First, respondents were asked about their involvement in patient handover ("how often are you involved in patient handover between departments?" with answer categories 'daily', '4-6 times a week', '2-3 times a week', 'once a week', 'less than once a week', '(almost) never'). Respondents answering '(almost) never' were immediately directed to the end of the survey. The remaining respondents were then asked about the general characteristics of patient handover, such as the way information is transferred (i.e. not specific to international handover) and how is communicated about these information transfers. Following the questions about handover in general, respondents were asked how often they had been involved in international handover during the past month (answer categories were 'never', '1-5 times', '6-10 times', '11-15 times', '16-20 times', '21 times or more'). If respondents answered 'never' they were directed to questions about procedures/checklists. The remaining respondents were asked about information transfer during international handover situations, and about checklists and procedures used both in general and in international handover situations. The topic of safety culture was dealt with in five statements that respondents could answer on a scale of 1 , 'strongly disagree' to 5, 'strongly agree'. They were asked how they perceive patient safety in their own hospital ("How would you grade patient safety during handover in your hospital/ institution?" on a scale of 1 , 'very negative' to 10 , 'very positive'). Then they were asked if they were trained specifically in international handover. Completing the survey were two open questions on the potential risks and possible solutions for patient safety: "What are the largest patient safety risks during (international) handover?" and "What should be done to improve patient safety during (international) handover?".

\section{Procedure}

The ethical review committee of MUMC + reviewed the study proposal (no. 2017-0100) and agreed the study does not fall under the Medical Research Involving Human Subjects Act. After the review, local requirements were followed to have data collection within the different settings approved. For instance, a request was written to the board of directors of the MUMC+ to obtain approval for data collection in their hospital. Potential respondents were approached via procedures that fitted local requirements. An estimated 1500 doctors and at least the same amount of nurses were reached and informed about this study. In the Belgian province of Limburg and the Dutch MUMC+, department heads consented to send the online survey link to their staff (14 contacts in Belgian Limburg and 59 contacts in 
MUMC+). In the Aachen region, CHR, and the Dutch province of Limburg, potential respondents were approached via existing mailing lists. Additionally, in CHR, the link to the survey was posted on the institution's intranet. In the province of Liège, UKA, and ZOL, researchers sent an e-mail to contact persons who forwarded the survey through the local institution. In all cases, two follow-up reminders were mailed to potential respondents, one and two weeks after the first e-mail. The survey stayed open for four weeks after initial distribution. Only fully completed surveys were included in the study.

\section{Analyses}

Descriptive data were analyzed in IBM SPSS 22 (IBM Corp., Armonk, NY) to explore and summarize the quantitative responses on the questions about (1) demographics, (2) general handover, (3) international handover, (4) procedures/checklists, (5) safety culture, and (6) trainings.

Qualitative data about (7) risks and solutions were analyzed in ATLAS.ti 8.1.0 (ATLAS.ti Scientific Software Development GmbH, Berlin) using an inductive thematic analysis procedure within the essentialist epistemology. The six-step approach described by Starmer et al. ${ }^{20}$ was used to structure the analysis. First, the data were translated to English, read, and re-read, while the researchers noted down primary coding ideas. Second, initial semantic codes were generated such that the codes refer to the most basic element of the raw data that can be meaningfully assessed. Two researchers (MEJB and JAB) went through the entire dataset in an iterative process, giving full attention to all items and coding all data extracts. After all data were coded, the third step involved searching for themes. Researchers (MEJB, JAB and DMLV) collated the codes into potential themes. Step four involved reviewing the initial themes, checking whether they fit all coded extracts (at the raw data level), resulting in a thematic map of the analysis. In step five, the final thematic map was created.

\section{Results}

Out of the estimated 3000 healthcare workers that were reached and informed by this study, a total of 846 respondents had taken the survey by the end of January 2018 (response rate $28.2 \%$ ).

\section{Demographics}

Healthcare workers from the four involved hospitals and emergency services, living in all the involved regions, contributed to the survey. The smallest group of respondents lives in the (German-speaking) East
Cantons of Belgium (3\%), followed by larger groups in Germany $(13 \%)$, Flanders $(18 \%)$, the Netherlands $(23 \%)$, and Wallonia (43\%). The sample comprised a variety of healthcare workers, both men $(53.5 \%)$ and women $(46.5 \%)$ aged between 18 and 74 years. Respondents included administrators (7.6\%), ambulance personnel (firefighters/paramedics) $(28.3 \%)$, medical doctors $(24.9 \%)$ and nurses (23\%). Respondents worked in more than 30 different departments, including emergency care $(17 \%)$, anesthesiology $(7 \%)$, radiology $(5 \%)$, pulmonology $(4 \%)$, and general surgery $(3 \%)$ (for a detailed overview see Table 1).

Table I. Characteristics of respondents.

\begin{tabular}{|c|c|c|}
\hline & $N=846$ & $\%$ \\
\hline \multicolumn{3}{|l|}{ Age category } \\
\hline $18-24$ & 35 & 4.1 \\
\hline $25-34$ & 239 & 28.3 \\
\hline $35-44$ & 255 & 30.1 \\
\hline $45-54$ & 214 & 25.3 \\
\hline $55-64$ & 98 & 11.6 \\
\hline $65-74$ & 5 & 0.6 \\
\hline \multicolumn{3}{|l|}{ Gender } \\
\hline Female & 393 & 46.5 \\
\hline Male & 453 & 53.5 \\
\hline \multicolumn{3}{|l|}{ Job title } \\
\hline Administrator & 64 & 7.6 \\
\hline Ambulance personnel & 239 & 28.3 \\
\hline Medical doctor & 211 & 24.9 \\
\hline Nurse & 195 & 23.0 \\
\hline Student & 2 & 0.2 \\
\hline Other & 129 & 15.2 \\
\hline Missing & 6 & 0.7 \\
\hline \multicolumn{3}{|l|}{ Work location } \\
\hline $\mathrm{CHR}$ & 250 & 29.6 \\
\hline MUMC & 203 & 24.0 \\
\hline RWTH & 48 & 5.7 \\
\hline ZOL & 25 & 3.0 \\
\hline Emergency service & & 31.2 \\
\hline Flanders & 68 & \\
\hline Wallonia & 100 & \\
\hline Germany & 56 & \\
\hline Netherlands & 23 & \\
\hline Other & 17 & \\
\hline Other & 54 & 6.5 \\
\hline \multicolumn{3}{|l|}{ Country of residence } \\
\hline East Cantons of Belgium & 23 & \\
\hline Flanders & 159 & \\
\hline Germany & 106 & \\
\hline Netherlands & 193 & \\
\hline Wallonia & 365 & \\
\hline Other & & \\
\hline
\end{tabular}

CHR de la Citadelle: le Centre Hospitalier Régional de la Citadelle, Belgium; MUMC+: Maastricht University Medical Center, Netherlands; RWTH: University Hospital RWTH Aachen, Germany; ZOL: Ziekenhuis Oost-Limburg Genk, Belgium. 
Table 2. General and international handover characteristics.

\begin{tabular}{|c|c|c|}
\hline$N=846$ & $n$ & $\%$ \\
\hline \multicolumn{3}{|c|}{ Frequency involved in general handover per week } \\
\hline Daily & 306 & 36.2 \\
\hline $4-6$ times & 110 & 13.0 \\
\hline $2-3$ times & 103 & 12.2 \\
\hline Once & 58 & 6.9 \\
\hline$<$ Once & 56 & 6.6 \\
\hline Almost never & 205 & 24.2 \\
\hline Missing & 8 & 0.9 \\
\hline$N=64 I$ & $n$ & $\%$ \\
\hline \multicolumn{3}{|l|}{ Information delivery general handover } \\
\hline Oral & 103 & I6. I \\
\hline Written & 54 & 8.4 \\
\hline Both & 481 & 75 \\
\hline Missing & 3 & 0.5 \\
\hline \multicolumn{3}{|l|}{ Information retrieval general handover } \\
\hline Oral & 172 & 26.8 \\
\hline Written & 85 & 13.3 \\
\hline Both & 370 & 57.7 \\
\hline Missing & 14 & 2.2 \\
\hline \multicolumn{3}{|c|}{ Frequency involved in international handover past month } \\
\hline$>20$ & 4 & 0.6 \\
\hline $16-20$ & 1 & 0.2 \\
\hline $11-15$ & 7 & I.I \\
\hline $6-10$ & 19 & 3.0 \\
\hline $\mathrm{I}-5$ & 223 & 34.8 \\
\hline Never & 387 & 60.4 \\
\hline$N=254$ & $n$ & $\%$ \\
\hline \multicolumn{3}{|l|}{ Type international handover } \\
\hline Acute & 106 & 41.7 \\
\hline Planned & 71 & 28 \\
\hline Both & 77 & 30.3 \\
\hline \multicolumn{3}{|c|}{ Information delivery international handover } \\
\hline Oral & 30 & 11.8 \\
\hline Written & 63 & 24.8 \\
\hline Both & 159 & 62.6 \\
\hline Missing & 2 & 0.8 \\
\hline \multicolumn{3}{|c|}{ Information retrieval international handover } \\
\hline Oral & 29 & 11.4 \\
\hline Written & 69 & 27.2 \\
\hline Both & 145 & 57.1 \\
\hline Missing & II & 4.3 \\
\hline$N=64 I$ & $n$ & $\%$ \\
\hline \multicolumn{3}{|c|}{ Available procedures/checklists for general handover (multiple answer-possibilities) } \\
\hline $\mathrm{ABCDE}$ & 342 & 53.4 \\
\hline (S)AMPLE & 311 & 48.5 \\
\hline (i)S(o)BAR & 204 & 31.8 \\
\hline None & 70 & 10.9 \\
\hline Unknown & 108 & 16.8 \\
\hline$N=641$ & $n$ & $\%$ \\
\hline \multicolumn{3}{|c|}{ Procedures/checklists are made available (multiple answer-possibilities) } \\
\hline On paper (A4) & 300 & 46.8 \\
\hline On paper (pocket-size) & 88 & 13.7 \\
\hline On posters & 28 & 4.4 \\
\hline On a computer & 180 & 28.1 \\
\hline On a portable electronic device & 39 & 6.1 \\
\hline
\end{tabular}


Table 2. Continued.

\begin{tabular}{|c|c|c|}
\hline$N=846$ & $n$ & $\%$ \\
\hline Not available & 145 & 22.6 \\
\hline$N=64 I$ & $n$ & $\%$ \\
\hline \multicolumn{3}{|l|}{ Frequency use procedures/checklists for regular handover } \\
\hline Always & 174 & 27.1 \\
\hline Mostly & 197 & 30.7 \\
\hline Half time & 21 & 3.3 \\
\hline Sometimes & 72 & 11.2 \\
\hline Almost never & 148 & 23.1 \\
\hline Missing & 29 & 4.5 \\
\hline$N=64 I$ & $n$ & $\%$ \\
\hline \multicolumn{3}{|l|}{ Procedures/checklists for general handover are used for international handover } \\
\hline Yes & 176 & 27.4 \\
\hline No, others for international handover & 19 & 3.0 \\
\hline No, there are none for international handover & 129 & 20.1 \\
\hline Unknown & 121 & 18.9 \\
\hline Missing & 196 & 30.6 \\
\hline \multicolumn{3}{|l|}{$N=64 I$} \\
\hline \multicolumn{3}{|l|}{ Patient safety culture, I 'strongly disagree' up to 5 'strongly agree' (Mean, SD) } \\
\hline Important information is often lost during handover & 3.21 & 1.03 \\
\hline It is clear what my tasks are during handover & 3.93 & 0.86 \\
\hline It is clear what other people's tasks are during handover & 3.56 & 0.90 \\
\hline Staff members from different institutions do not understand each other & 2.83 & 0.87 \\
\hline Standardized procedures are used in a meaningful way & 3.09 & 0.92 \\
\hline Perceived quality of care, I 'very low' up to 10 'very high' (Mean, SD) & 6.84 & 1.41 \\
\hline$N=254$ & $n$ & $\%$ \\
\hline \multicolumn{3}{|l|}{ International handover training at the workplace $(\mathrm{cme})$} \\
\hline Yes & 37 & 14.6 \\
\hline No & 217 & 85.4 \\
\hline
\end{tabular}

\section{General handover}

More than a third of all respondents $(36.2 \%)$ were involved in general handover on a daily basis, whereas a quarter $(24.2 \%)$ were (almost) never involved in a handover. Because respondents not involved in handovers were immediately directed to the end of the survey, 641 respondents completed the full survey.

Of the 641 respondents regularly involved in handover, $75 \%$ reported that they generally deliver information to colleagues during a handover by oral and written communication, and $58 \%$ reported that information was provided to them via oral and written communication.

\section{International handover}

Of the 641 respondents involved in general handover, 387 reported that they had never been involved in international handover leaving 254 respondents who had been involved in international handover in the previous month. Depending on the location, international handovers involved mostly elective care (e.g. for scheduled surgery), acute care (e.g. in case of an emergency), or both.

\section{Procedures/checklists}

Respondents mentioned various standardized procedures and checklists for general handovers in local settings. ABCDE, (S)AMPLE, and (i)S(o)BAR, checklists for healthcare workers to communicate clearly about the patient's status, were reported most often. A total of 16 other checklists/procedures were mentioned. However, $17 \%$ of the 641 respondents did not know which checklists were used for general handover in their department and $11 \%$ reported 'no checklist is used for general handover'. The frequency of checklist use varied particularly between hospitals: in one institution $54 \%$ of respondents 'almost never to use checklists/procedures', while in another $48 \%$ of respondents 'always use them'. The majority of respondents from the various emergency services said that checklists were used always or at least most of the time.

Checklists and procedures used for international handover were similar to those available for general 
handover in $27.4 \%$ of the 641 responses. Again, ABCDE, (S)AMPLE, and (i)S(o)BAR were mentioned most often. Another $29 \%$ of respondents said there were no checklists for international handover, and $27 \%$ of respondents did not know if or what checklists were available for international handover. Only $3 \%$, or 19 respondents, said that other checklists were available.

\section{Safety culture}

Patient safety culture was graded with an average of 3.3 on a scale of $1-5(\mathrm{M}=3.32, \mathrm{SD}=0.43)$. Respondents graded patient safety in their hospital with 6.8 out of 10 points (with 1 'very low' and 10 'very high'; $\mathrm{M}=6.84$; $\mathrm{SD}=1.41)$.

\section{Training}

Of the 254 respondents involved in international handover, $217(85 \%)$ had not received training in international handover. Respondents who had been trained mentioned a variety of topics and forms of training. Examples include specific training in using standardized procedures such as ABCDE or SBAR, on-thejob feedback about communication during handover, e-mailed instructions for new procedures, weekly clinical lessons on a variety of topics, and information provision through an electronic learning environment. See Table 2 for a detailed overview of the above mentioned topics.

\section{Risks and solutions}

To the open-ended questions on risks and solutions, 408 respondents entered risk factors for international handover and 373 respondents entered solutions. After analyzing the responses, six key themes were identified and explained below, illustrated by quotes (see Figure 2).

Awareness. Risks regarding awareness concerned differences in expectations, assumptions, rules of engagement, and work culture: "(...) foreign doctors do not see us as equal partners." [R822; ambulance nurse]. Solutions point toward gaining a better understanding of each other's norms and values. For example, an ambulance nurse [R830] wrote: "mutual understanding - it might be good to look at each other (...) for both the driving services and the hospitals." The major solution/ necessity respondents mentioned was 'getting to know each other' ("Introduction day for specialists" [R710; surgeon]), which could lead to workers to share their expectations and learn from each other.
Professional competencies. The respondents mentioned different levels of training, qualification, and competences as risk factors. In some countries there is always a doctor in the ambulance, whereas in other countries it is a specialized nurse or a paramedic, e.g.: "Ambulance services do not always have a nurse on board and so there is not always a thorough search for specific pathology, just for a simple explanation of the manifest symptoms" [R210; ambulance nurse]. R73 [ambulance nurse] mentions another problem that differences in competencies raises: "The very different training levels of the parties involved (rescue service, care, doctors) lead to strict hierarchical thinking and mutual incomprehension." Several solutions were mentioned, pointing toward equal requirements for personnel across Europe, and assessment and training in competencies.

Communication between healthcare workers.

Communication (or the lack of it) was mentioned as a risk factor more than 50 times. Respondents mentioned a broad range of topics on communication, from literally not understanding each other, ("errors or misunderstandings because of the language barrier" [R338; emergency physician]), to not communicating at all, ("not telling them that the transfer will take place" [R667; cardiovascular surgeon]). A broad range of solutions was suggested, including using clear language, and improving communication with training, as [R53; anesthesiologist] suggests: "Comprehensive and cross-departmental training in 'Human Factors' and training opportunities."

Information loss. Terms like 'information loss' and 'incomplete patient information' were mentioned frequently. The reasons included difficulties in the registration process, lack of a uniform (documentation) system, inexperienced colleagues involved, and too many transfer moments for one patient. R73 [ambulance nurse] explained: "Due to the lack of a uniform system and the lack of documentation for information previously collected on the patient, anything that does not seem important is quickly discarded and not passed on." R741 [pulmonary nurse] stated: "Important information gets missed so that compromises patient safety, or they do unnecessary examinations which harm the patient and increase the medical expenses." Many solutions were provided, pointing toward clear agreements about responsibilities, standardized procedures, and provision of feedback after transfers: "Digital file with step-by-step handover that can be accessed with a code, and where the recipient can directly assessed imaging." [R660; orthopedist].

Facilities and support. Problems with facilities and support in international handover were seen as a big risk 


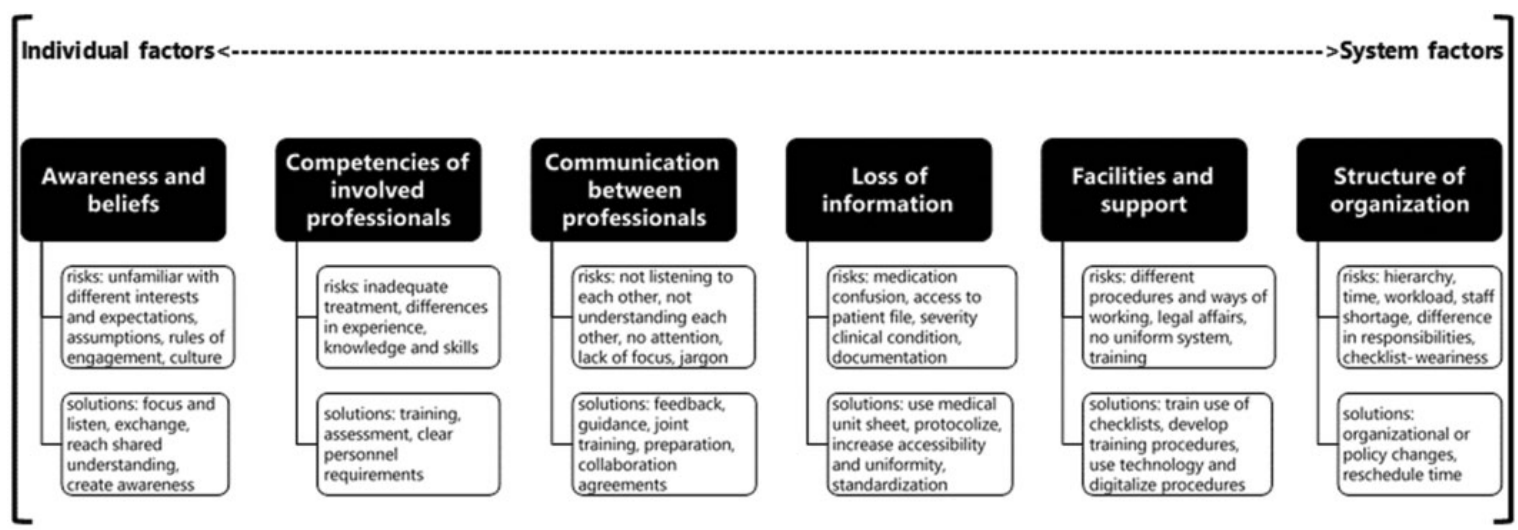

Figure 2. Spectrum of patient safety risks and solutions.

for patient safety: here the frequently mentioned topics covered differences in procedures, legal affairs, and the lack of uniform systems. Solutions focused on training, for example: "More training in the standard transfer forms (...) and how you can best use them (...) and also make it mandatory to do the transfer in the same way." [R807; occupational therapist]. Striving for uniformity was also mentioned as a solution: "The concept should only be unified ... an international transfer would make a lot of sense!" [R20; ambulance nurse]. And, implementing technical solutions was mentioned often: "Common IT platform with adequate data security" [R648; cardiologist].

Organization structure. The structure of the organization encompasses staff responsibilities, workload, hierarchy, and time. As [R73; ambulance nurse] says: "The extreme shortage of nursing staff also puts a lot of (temporary) pressure on colleagues, who thus a) have less time to hand over and b) cannot fully concentrate on the specific patient." It seems that the organization of international handovers plays an important role: "What I do find a disadvantage as an ambulance [arriving] in a foreign hospital, you first have to get the patient registered before you can transfer them to the emergency room or some other department." [R838; ambulance nurse]. The solutions for problems with structure mostly concern organizational or policy awareness and changes: "Provision of information about the different healthcare institutions and their working methods. The function and their duties and powers" [R843; ambulance nurse].

\section{Discussion}

The current study revealed that one-third of the respondents was involved in international patient handover in the past month. Respondents were mostly not trained for this, and approached these handovers similar to general handovers in their hospital. However, because of additional challenges of international patient handovers, respondents experienced extra patient safety risks. These risks were categorized in six categories where both individual and system factors seemed to play a role. Often these factors were characterized by differences between local settings. The respondents provided many possible solutions to improve patient safety in international patient handover. These ranged from evening out differences by harmonizing tools, procedures, or even languages, up to developing inter-professional, international training programs to be better prepared for international patient handover and collaboration with colleagues across the border.

Earlier studies already provided a lot of information about the risks of patient handovers in general. Some of these findings were confirmed again in the present study. Standardizing or harmonizing procedures would add safety and decrease failure. ${ }^{1,11,21-23}$ Further, the inability to share patient information directly with colleagues across the border often leads to loss of information, which results in unnecessary repetitions of medical examinations and treatment delays. Being able to share patient information digitally would ease the handover process for healthcare workers. ${ }^{1,11}$ Facilitating the digital exchange of medical information between countries ${ }^{1}$ would provide the necessary support, easing the handover process for both patients and healthcare workers, and decreasing the risk of medical mistakes due to incomplete information.

The current study provides a broader perspective on the added risks of the international component of handover in a cross-border region. The added complexity lies in the fact that healthcare workers with different educational backgrounds, competencies and responsibilities have to collaborate with colleagues in healthcare systems that are organized differently, with different rules within a different organizational culture. 
All these differences add complexity to patient handover on many levels. However, based on the results of our study we believe that the biggest risk of international patient handover lies not in these differences themselves, but in the perspective of the healthcare workers who have to deal with these differences.

Being unaware of (differences in) each other's responsibilities and competencies or organizational culture can add major risks to an event like patient handover. ${ }^{11}$ This was frequently stressed by respondents of the present study, too. They often mentioned a need and desire for a better mutual understanding with colleagues across the border. They seek for clarity about differences in competencies and what they can or may expect from peers across the border. They want to be listened to, regardless of differences in position or hierarchical status. They want to provide the best care possible, together, in a constructive way. Having more insight in this challenging aspect of international patient handover gives already some direction regarding possible solutions to improve the situation, especially because these results show the willingness among healthcare workers. The respondents specified several ideas for overcoming this unawareness, getting to know each other better by organizing regular meetings, international internships, workshops and trainings to learn about each other's way of working and each other's healthcare system. Facilitating healthcare workers in their efforts to improve international patient handover is an important first step in decreasing the patient safety risks.

This study has several limitations. First, the explorative character did not allow us to use an existing, validated survey. Second, we focused strongly on healthcare workers' perspectives. Future studies might consider other stakeholders' perspectives, such as patients. Third, most respondents worked in academic hospitals, which generally offer many educational opportunities for staff members. Therefore, this study might contain an overrepresentation of healthcare workers with higher levels of training.

It is already known that patient handover is a risky event. ${ }^{11}$ For future studies it would be interesting to find out to what extent the added risks of international patient handover have put patients at extra harm. Furthermore, the present study was developed to provide a broad view on the complexity of international patient handover in a specific border-region. As specific challenges associated with international patient handover are likely different across specialties/disciplines, focus on specific settings where international handover frequently takes place may provide more in-depth insight. Those insights could reveal how to deal with specific problems associated with international handover. Lastly, to get a complete picture of the specific challenges of international patient handover, perspectives of other stakeholders, such as patients, should be included as well.

The large amount of opportunities that were put forward in this study add valuable insight in the way working on the improvement of international patient handover in the border-region should be continued. As suggested by the respondents, some local differences can be evened out. In the collaboration between healthcare workers, e.g. the ambulance service in one country and the emergency department in another country, healthcare workers could agree on using the same procedures and checklists and a language that all those involved can understand. However, some differences are harder to overcome, for example: the education of healthcare workers, health insurance arrangements, the task division between physicians and nurses, to name but a few. As already mentioned earlier, it is vital that healthcare workers are aware of these differences and learn how to collaborate with their peers across the border, taking their differences into account. This requires knowledge, but also the opportunity to get to know each other and train together. Future initiatives should focus on creating these opportunities in specific international handover situations. In conclusion, international patient handover is complex and has many practical obstacles due to local differences in the organization of healthcare. The information transfer is not only hampered by language differences, but also by differences in information storage, procedures, division of responsibilities, etc. Healthcare workers may not always be aware of these differences, which might lead to negative perceptions of those on 'the other side'. At the same time, the notion that healthcare workers in each setting seem to struggle with similar difficulties and that they ultimately serve the same professional goal may form a mutual starting point to start the dialogue with colleagues across the border. Considering international collaboration is stimulated in border-regions, and healthcare workers in this region all share the same interest in providing highquality care to their patients, the results of this study are a valuable starting point to further optimize international patient handovers.

\section{Declaration of conflicting interests}

The author(s) declared no potential conflicts of interest with respect to the research, authorship, and/or publication of this article.

\section{Funding}

The author(s) disclosed receipt of the following financial support for the research, authorship, and/or publication of this article: This study is part of the SafePAT project by Interreg V-A Euregio Meuse-Rhine (project number EMR90). This project is co-financed by the European Union and the 
European Regional Development Fund. For more information about the project go to www.safepat.eu.

\section{ORCID iD}

Mara EJ Bouwmans (D) https://orcid.org/0000-0002-86631203

\section{References}

1. Glonti K, Hawkesworth S, Footman K, et al. European health professionals' experience of cross-border care through the lens of three common conditions. Eur $J$ Integr Med 2015; 7: 29-35.

2. General Secretary of the Benelux Union. Patients without borders. Cross-border patient flows in the Benelux. Brussels: Author, 2016.

3. Wagner C, Dobrick K and Verheyen F. EU cross-border health care survey 2010. Planned cross-border care-physicians and dentists from TK Insurants perspective. WINEG Wissen 2013; 3.

4. Legido-Quigley H, Glinos I, Baeten R, et al. Patient mobility in the European Union. Bmj. 2007; 334: 188-190.

5. Tol JA, van Gulik TM, Busch ORC, et al. Centralization of highly complex low-volume procedures in upper gastrointestinal surgery. A summary of systematic reviews and meta-analyses. Dig Surg 2012; 29: 374-383.

6. Starmans B, Leidl R and Rhodes G. A comparative study on cross-border hospital care in the Euregio MeuseRhine. Eur J Public Health 1997; 7: 33-41.

7. Ruggeri $\mathrm{K}$ and Hinrichs-Krapels S. Editorial: global health and medical travel. Front Public Health . 2016; 4: 235-210.

8. Australian Medical Association. Safe handover: safe patients. Guidance on clinical handover for clinicians and managers. Canberra: Author, 2006.

9. Eggins $\mathrm{S}$ and Slade D. Communication in clinical handover: improving the safety and quality of the patient experience. J Public Health Res 2015; 4: 666-666.

10. Kripalani S, LeFevre F, O Phillips CO, et al. Deficits in communication and information transfer between hospital-based and primary care physicians: implications for patient safety and continuity of care. JAMA 2007; 297: 831-841.

11. Lawton R, McEachan RRC, Giles SJ, et al. Development of an evidence-based framework of factors contributing to patient safety incidents in hospital settings: a systematic review. BMJ Qual Saf 2012; 21: 369.

12. Merten H, van Galen LS and Wagner C. Safe Handover. BMJ 2017; 359: j4328.

13. Redley B, Botti M, Wood B, et al. Interprofessional communication supporting clinical handover in emergency departments: an observation study. Australas Emerg Nurs $J$ 2017; 20: 122-130.

14. Abdellatif A, Bagian JP, Barajas ER, et al. Communication during patient hand-overs: patient safety solutions, volume 1, solution 3, May 2007. Joint Commission Journal on Quality and Patient Safety 2007; 33(7): 439-442.

15. Glinos IA and Baeten R. Reprint of: dream vs. reality: seven case-studies on the desirability and feasibility of cross-border hospital collaboration in Europe. Soc Sci Med 2015; 124: 331-314.

16. Beuken JA-O, Verstegen DML, Dolmans D, et al. Going the extra mile - cross-border patient handover in a European border region: qualitative study of healthcare professionals' perspectives. BMJ Qual Saf 2020; 29: 980 987.

17. Jabakhanji SB, Meier TM, Ramakers-van Kuijk MA, et al. Agreements and practical experience of trauma care cooperation in Central Europe: the "Boundless Trauma Care Central Europe" (BTCCE) project. Injury 2015; 46: 519-524.

18. Brand H, Hollederer A, Wolf U, et al. Cross-border health activities in the Euregios: good practice for better health. Health Policy 2008; 86: 245-254.

19. Nieva VF and Sorra J. Safety culture assessment: a tool for improving patient safety in healthcare organizations. Qual Saf Health Care 2003; 12 Suppl 2: ii17-23.

20. Braun V and Clarke V. Using thematic analysis in psychology. Qual Res Psychol 2006; 3: 77-101.

21. Starmer AJ, Sectish TC, Simon DW, et al. Rates of medical errors and preventable adverse events among hospitalized children following implementation of a resident handoff bundle. JAMA 2013; 310: 2262-2270.

22. Starmer AJ, O'Toole JK, Rosenbluth G, et al. Development, implementation, and dissemination of the I-PASS handoff curriculum: a multisite educational intervention to improve patient handoffs. Acad Med 2014; 89: 876-884.

23. Starmer AJ, Spector ND, Srivastava R, et al. Changes in medical errors after implementation of a handoff program. N Engl J Med 2014; 371: 1803-1812. 